\title{
Presidents' INAUGURAL ADDRESS Philippine Society of Otolargyngology Head and Neck Surgery Annual Congress December 2, 2015
}

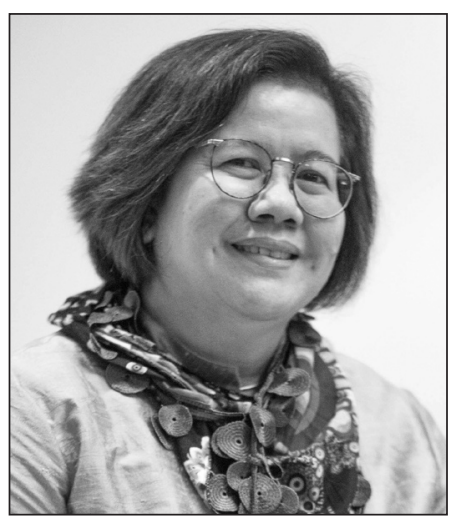

Past Presidents of the PSO-HNS especially founding President Dr. Tierry Garcia, President of the PBO-HNS Dr. Rudy Nonato, Presidents of the chapters and Chairs of the subspecialty groups, co-Fellows of the society, friends, guests, ladies and gentlemen.

At the threshold of the 60th anniversary of this venerable society, I stand here today as the humble recipient of your trust and confidence as your President. As a child I have seen the photos of the heroic founders and had been witness to the lasting friendship between them. I was in high school when my father, Dr. Armando T. Chiong, Sr. became the 10th President of the organization. I now follow my brother, President Dr. Armando Chiong, Jr. to continue the programs he started. Such laudable programs started by the past years' BOT with the advocacy map, public awareness, chapter and institutional initiatives will be continued. With the funding earmarked from the proceeds of the Diamond Jubilee celebration on April 2016, Research and Academic programs will be strengthened and the society's journal the PJO-HNS will move for even more international recognition.

The breadth and the depth of human capacity to help one another is limitless. The same can be said for our organization whose dedicated fellows strive for excellence in their clinical practice with honor and integrity.

Make no mistake that it is a privilege being here amongst you my co-dreamers for a society that will be recognized not only for its international standing, its global perspective, its innovations but for its sincere quest for helping raise the quality of lives to heal the sick among our countrymen and render the best ENT care possible at an affordable cost and of wider availability.

We thank our mentors for the great example they have given us, their wisdom and good counsel so all of us 694 fellows united can champion the cause of the patients we serve.

The PSO-HNS will use all its available resources to move the organization forward to work more closely with partners in industry, government, non-government, academic institutions and each fellow, chapter, and subspecialty group will be supported by your BOT in these endeavors.

Lead, we will. Serve with dedication in our best capacity for sure and we trust in your full support of our institution.

We stand proud of this prestigious society of the best experts in ENT care. The growth of PSO-HNS from the 'heroic 9' to 694 in 60 years is phenomenal. Challenges, there will be always be but in the end we will know that more is yet to be done and the future brilliant because the legacy will always remain. See you all in the anniversary ball in February and the Jubilee celebration in April, 2016 organized by Dr. Dan Poblete. Good evening to you all. 